\title{
Mechanical properties of sand, silt, and clay containing tetrahydrofuran hydrate
}

\author{
T. S. Yun, ${ }^{1}$ J. C. Santamarina, ${ }^{1}$ and C. Ruppel ${ }^{2,3}$ \\ Received 4 May 2006; revised 14 November 2006; accepted 27 December 2006; published 17 April 2007.
}

[1] The mechanical behavior of hydrate-bearing sediments subjected to large strains has relevance for the stability of the seafloor and submarine slopes, drilling and coring operations, and the analysis of certain small-strain properties of these sediments (for example, seismic velocities). This study reports on the results of comprehensive axial compression triaxial tests conducted at up to $1 \mathrm{MPa}$ confining pressure on sand, crushed silt, precipitated silt, and clay specimens with closely controlled concentrations of synthetic hydrate. The results show that the stress-strain behavior of hydrate-bearing sediments is a complex function of particle size, confining pressure, and hydrate concentration. The mechanical properties of hydrate-bearing sediments at low hydrate concentration (probably $<40 \%$ of pore space) appear to be determined by stress-dependent soil stiffness and strength. At high hydrate concentrations ( $>50 \%$ of pore space), the behavior becomes more independent of stress because the hydrates control both stiffness and strength and possibly the dilative tendency of sediments by effectively increasing interparticle coordination, cementing particles together, and filling the pore space. The cementation contribution to the shear strength of hydrate-bearing sediments decreases with increasing specific surface of soil minerals. The lower the effective confining stress, the greater the impact of hydrate formation on normalized strength.

Citation: Yun, T. S., J. C. Santamarina, and C. Ruppel (2007), Mechanical properties of sand, silt, and clay containing tetrahydrofuran hydrate, J. Geophys. Res., 112, B04106, doi:10.1029/2006JB004484.

\section{Introduction}

[2] Clathrate hydrates or gas hydrates consist of a hydrogenbonded water lattice surrounding a guest molecule of such natural gases such as $\mathrm{CH}_{4}, \mathrm{C}_{2} \mathrm{H}_{6}, \mathrm{CO}_{2}$, or $\mathrm{H}_{2} \mathrm{~S}$. Methane gas hydrate, the most common type occurring in nature, forms at pressure and temperature conditions common in the uppermost tens to hundreds of meters of sediments in permafrost regions and marine continental margins. Much of the research on natural hydrate deposits has been prompted by their potential as an energy source and by their association with submarine slope failures and global climate change events.

[3] Despite considerable interest in the properties of clathrate-bearing sediments, the mechanical properties of these sediments remain poorly known. Past approaches for studying these properties have included theoretical analyses, nondestructive characterization of in situ deposits, and laboratory measurements on synthetic and recovered samples. Each of these approaches has inherent difficulties. For example, theoretical studies based on borehole-scale or field-scale observational data [e.g., Ecker et al., 2000; Lee

\footnotetext{
${ }^{1}$ School of Civil and Environmental Engineering, Georgia Institute of Technology, Atlanta, Georgia, USA.

${ }^{2}$ School of Earth and Atmospheric Sciences, Georgia Institute of Technology, Atlanta, Georgia, USA.

${ }^{3}$ Now at U.S. Geological Survey, Woods Hole, Massachusetts, USA.

Copyright 2007 by the American Geophysical Union. 0148-0227/07/2006JB004484\$09.00
}

and Collett, 2001; Lee, 2002; Chand et al., 2004] require assumptions that are not always readily justifiable. The nondestructive seismic approaches described by Hyndman and Spence [1992], Mi et al. [1999], and Pecher and Holbrook [2000] provide insight about the small-strain seismic response but not about the behavior of hydratebearing sediment at large strains. Direct sampling and subsequent laboratory measurements [e.g., Yun et al., 2006] cause disturbance and degradation of in situ properties even when coring techniques preserve in situ fluid pressure (i.e., so-called pressure coring). The results of laboratory measurements on pure hydrates [e.g., Durham et al., 2003a, 2003b] are difficult to extrapolate to hydratesediment mixtures. Laboratory studies on sediments containing synthetic gas hydrate [e.g., Durham et al., 2005; Masui et al., 2005; Ebinuma et al., 2005] may therefore constitute a more valuable approach to exploring the mechanical properties of gas hydrate-bearing sediments under closely controlled conditions. In this paper, we describe laboratory studies designed to systematically explore intermediate and large-strain mechanical properties of tetrahydrofuran (THF)-hydrate-bearing sand, silt, and clay with different hydrate concentrations and subject to different effective confining pressures.

\section{Methods}

[4] To measure the strength of hydrate-bearing sediments and to study how hydrate interacts with various soils, we tested four materials (sand, crushed silt, precipitated silt, 


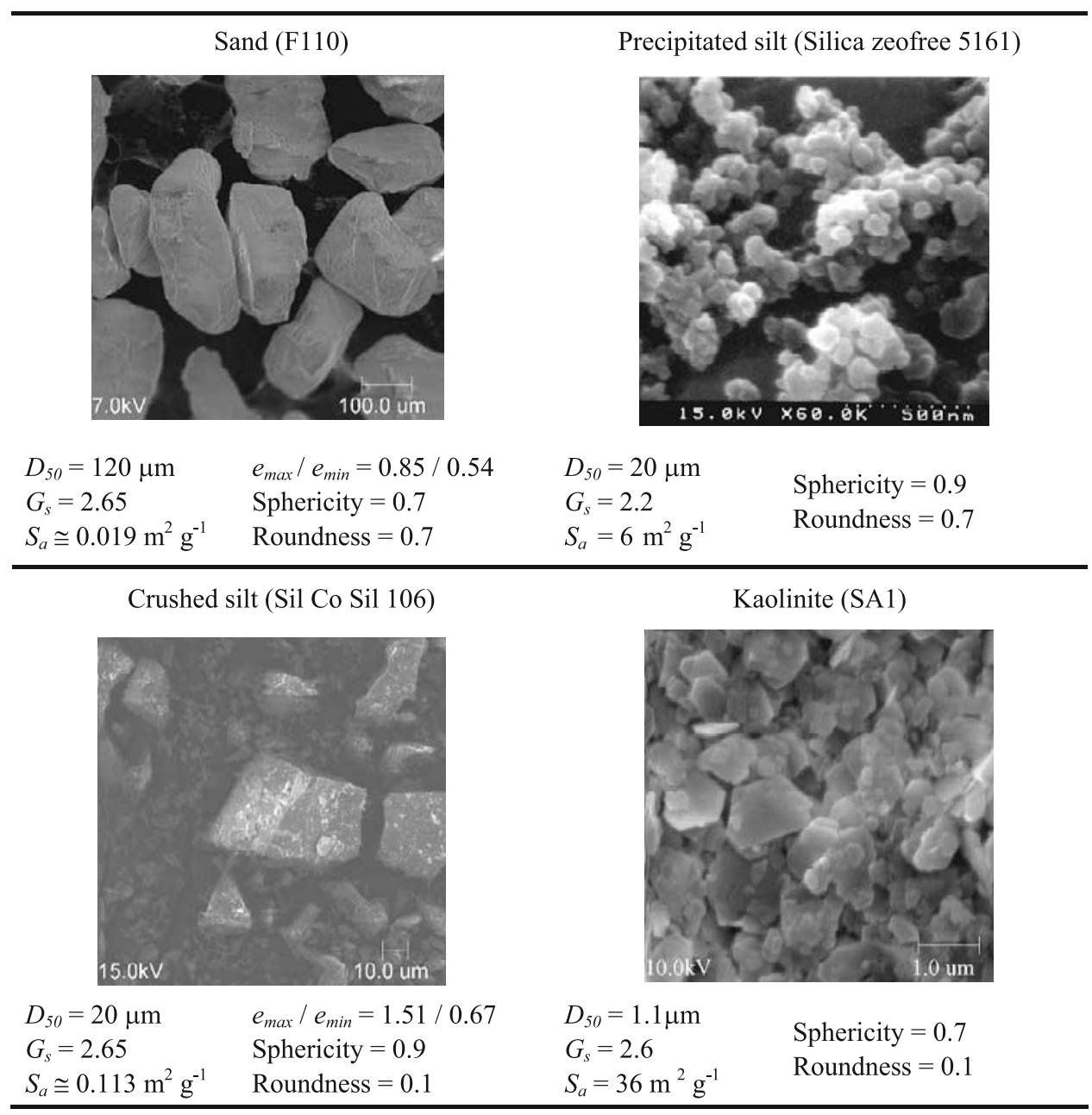

Figure 1. Characteristics of tested soils, compiled from Santamarina and Cho [2001], Klein [1999], Parks [1990], and Guimaraes [2001]. Specific surface for kaolinite and precipitated silt was measured using methylene blue (wet method). SEM pictures were provided by A. Palomino.

and kaolinite) and synthesized THF hydrate to a saturation $S_{\text {hyd }}$ of 0,50 , and $100 \%$ of sample porosity. The chosen sediments represent a broad range of the lithologies present in natural hydrate-bearing systems. The four selected soils cover a mean particle size $D_{50}$ of $1.1 \mu \mathrm{m}$ (kaolinite) to $120 \mu \mathrm{m}$ (sand) and specific surface $S_{\mathrm{a}}$ of $0.019 \mathrm{~m}^{2} \mathrm{~g}^{-1}$ (sand) to $36 \mathrm{~m}^{2} \mathrm{~g}^{-1}$ (kaolinite). Figure 1 shows other characteristics and scanning electron microscope (SEM) images of the tested soils. Note that the specific surface of precipitated silt $\left(S_{\mathrm{a}}=6 \mathrm{~m}^{2} \mathrm{~g}^{-1}\right)$ is larger than that of crushed silt $\left(S_{\mathrm{a}}=\right.$ $0.013 \mathrm{~m}^{2} \mathrm{~g}^{-1}$ ) even though their mean size $D_{50}$ values are the same. This observation indicates that precipitated silt includes internal pores, similar to natural grains such as diatoms. Because some physical properties are correlated more strongly with specific surface than grain and pore size, laboratory measurements on precipitated silt do not always yield results that follow the anticipated ordering of clay-silt-sand for each property.

\subsection{Testing Instrumentation}

[5] The samples were confined to effective pressures $\sigma_{0}^{\prime}$ of $0.03,0.5$, and $1 \mathrm{MPa}$ in a triaxial cell modified to include sensors for monitoring specimen deformation and thermocouples for detection of the hydrate phase transformation.

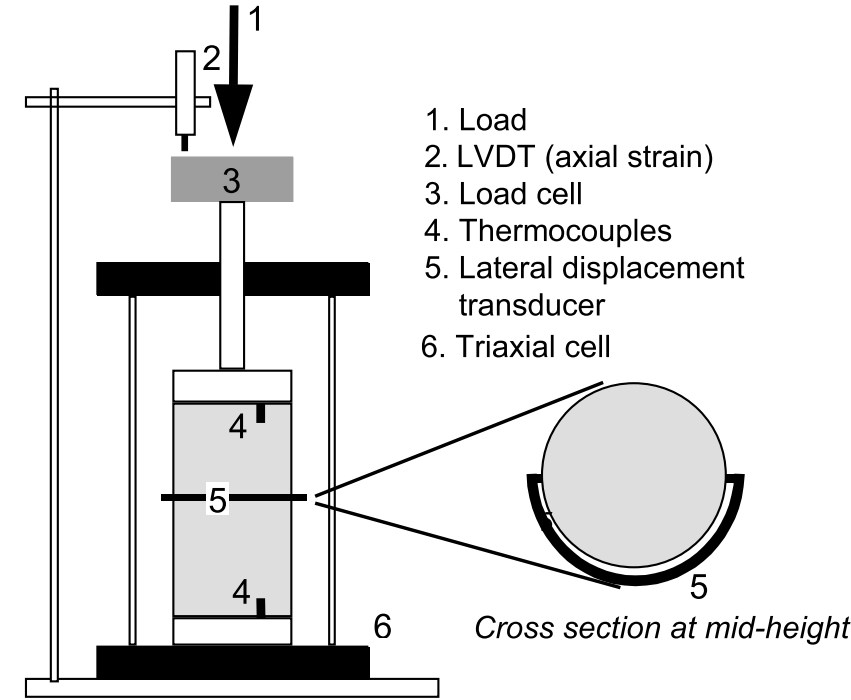

Figure 2. Modified triaxial cell and peripheral electronics. Thermocouples are embedded on the top and bottom plates, and a strain-gauged arch is mounted at the middle height of the specimen. LVDT denotes linear variable displacement transducer. 


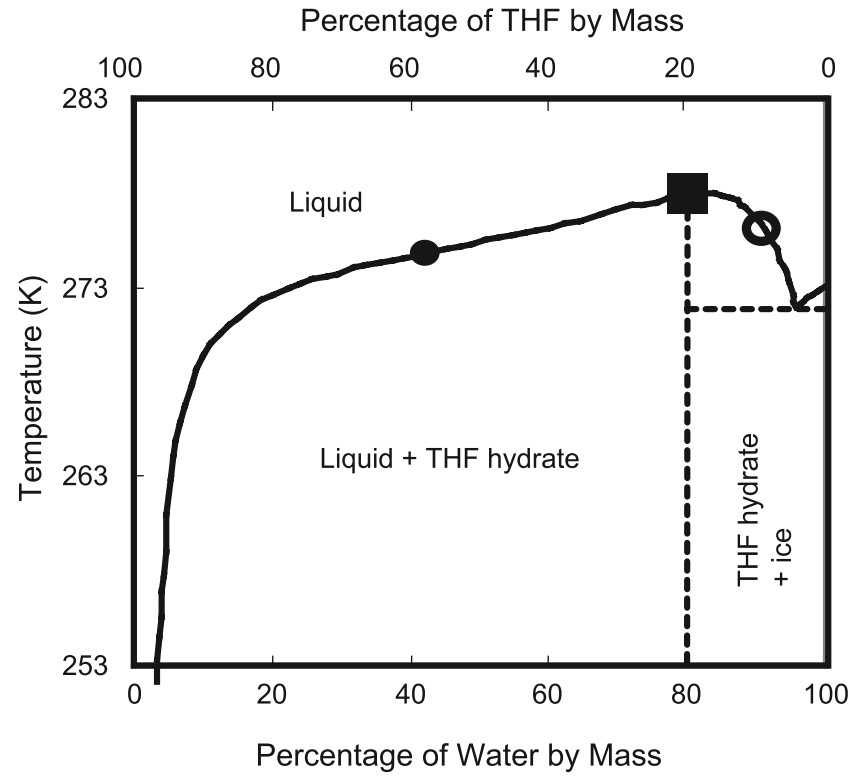

Figure 3. Phase diagram for the THF-water system at atmospheric pressure. THF-water mixtures marked by the open and solid circles will both produce $50 \%$ hydrate in pore space, but the mixture denoted by the solid circle was used for this study since it results in excess THF, not water, upon hydrate formation. The square corresponds to the THF-water mixture required to produce $100 \%$ hydrate in pore space.

Details of the modified cell are shown in Figure 2. Lateral displacement is measured with a metal arch instrumented with two strain gauges in a full bridge configuration [Goto et al., 1991]. The two active gauges are installed on opposite sides of a thin metal arch so that one gauge measures compression and the other measures tension. This full bridge configuration minimizes nonlinear and temperature effects. The resolution of this lateral displacement sensor is $\sim 10 \mu \mathrm{m}$. The instrumented arch is calibrated with a digital caliper under different temperature ranges, and its performance is verified with the direct measurement of lateral displacement in a dummy specimen.

\subsection{Hydrate Formation}

[6] The greatest challenge for laboratory studies of the properties of hydrate-bearing sediments is the synthesis of methane hydrate in a manner consistent with the formation of hydrate in natural systems. While it has long been known that porous methane hydrate can form very rapidly in the presence of gaseous methane, most methane hydrate in natural marine sediments is believed to form from aqueous phase methane [e.g., Buffett and Zatsepina, 2000] whether transported by diffusion and/or advection. In light of the very low solubility of methane in water, the formation of methane hydrate from aqueous phase methane requires long specimen preparation time if high hydrate saturation is sought [e.g., Yun et al., 2005; Spangenberg et al., 2005].

[7] One common approach in laboratory experiments has been the flushing of methane gas through initially partially or fully saturated porous media [e.g., Helgerud et al., 1999; Waite et al., 2004; Winters et al., 2004]. The implications of this technique for hydrate formation and sediment properties have been partially explored by Spangenberg et al. [2005] and Chand et al. [2006]. For studies of properties that depend on the microscale distribution of gas hydrate, the most important effects of flushing methane gas through initially partially or fully water-saturated sediments may be the development of gas percolation paths, the rapid hydrate formation around bubbles, and the biasing of the spatial distribution of hydrates toward interparticle contacts. Hydrate formation at particle contacts is predicted to be a particular problem for initially partially saturated sediments where water is found in the pendular regime (i.e., at particle contacts). Surfactants have been used by some workers to reduce interfacial tension between gas and water phases [Zhong and Rogers, 2000; Woods, 2004; Sun et al., 2004], but these substances may fundamentally alter the process of hydrate crystallization.

[8] The ice-seeding method pioneered by Stern and Kirby [1998] has been used in a range of studies [e.g., Waite et al., 2002; Ebinuma et al., 2005; Masui et al., 2005]. Optical studies have shown that hydrate formed by this technique resembles samples recovered from marine and permafrost sediments [e.g., Durham et al., 2005]. Yet the sequence of events in this hydrate-formation technique deviates from that in natural systems, and concerns remain about the locus of hydrate formation [Spangenberg et al., 2005; Spangenberg and Kulenkampff, 2005] and the impact of the hydrate-formation mechanism and nucleation sites on the measured properties of the hydrate-bearing sediment [e.g., Priest et al., 2005].

[9] In part to overcome the difficulties associated with forming methane hydrate in a manner consistent with its crystallization from aqueous methane in real sediments, we choose THF as the guest molecule. THF hydrate has been widely used as a proxy for methane hydrate [Gough and Davidson, 1971; Rueff and Sloan, 1985; Pearson et al., 1986; Cameron et al., 1990; Devarakonda et al., 1999; Parameswaran et al., 1989], and its properties have been explored in detail by other workers [Carey, 1987; Smallwood, 1996]. Although the THF molecule is distinct from the methane molecule in terms of size, polarizability, and other characteristics, it presents important advantages for this study. In particular, THF is completely miscible in water, and all the THF necessary for the desired final pore saturation of hydrate can be mixed with the pore fluid from the outset of the experiment. This facilitates the synthesis of well-characterized hydrate-bearing specimens and allows us to properly reproduce important geological conditions that can play a significant role in controlling the mechanical properties of hydrate-bearing sediments, particularly the effective stress prior to hydrate formation.

[10] The ratio between THF and water in the initial mixture controls hydrate concentration in pore space, as demonstrated on the phase diagram in Figure 3. At atmospheric pressure, THF hydrate fills $100 \%$ of pore space when $81 \%$ water is combined with $19 \%$ THF by mass. Specimens with $50 \%$ hydrate-filled porosity are obtained by mixing either 91\% water and 9\% THF (produces excess water) or $43 \%$ water and $57 \%$ THF (produces excess liquid that is $95 \% \mathrm{THF}$ at $-10^{\circ} \mathrm{C}$ ). The freezing point of the excess THF is $-108.5^{\circ} \mathrm{C}$, compared with $0^{\circ} \mathrm{C}$ for the excess water case. The $43 \%$ water and $57 \%$ THF mixture is therefore a better choice for laboratory experiments on 
Table 1. Specimen Characteristics and Experimental Results

\begin{tabular}{|c|c|c|c|c|c|c|}
\hline & $\begin{array}{l}\text { Hydrate } \\
\text { Saturation } S_{\text {hyd }}, \%\end{array}$ & $\begin{array}{c}\text { Effective Confining } \\
\text { Stress } \sigma_{0}^{\prime}, \mathrm{MPa}\end{array}$ & $\begin{array}{c}\text { Initial } \\
\text { Void Ratio }\end{array}$ & $\begin{array}{c}\text { Void Ratio at the } \\
\text { End of Consolidation }\end{array}$ & $\begin{array}{c}\text { Peak Measured } \\
\text { Shear Strength } q_{\max }, \mathrm{MPa}\end{array}$ & $\begin{array}{c}\text { Secant Stiffness } \\
E_{50}, \mathrm{MPa} \\
\end{array}$ \\
\hline \multirow[t]{9}{*}{ Sand } & 0 & 0.03 & 0.61 & 0.60 & 0.12 & 16 \\
\hline & 0 & 0.5 & 0.61 & 0.60 & 0.79 & 105 \\
\hline & 0 & 1 & 0.63 & 0.60 & 1.41 & 275 \\
\hline & 50 & 0.03 & 0.60 & 0.59 & 1.54 & 413 \\
\hline & 50 & 0.5 & 0.61 & 0.57 & 1.93 & 405 \\
\hline & 50 & 1 & 0.61 & 0.56 & 2.71 & 483 \\
\hline & 100 & 0.03 & 0.58 & 0.59 & 8.01 & 854 \\
\hline & 100 & 0.5 & 0.60 & 0.58 & 8.77 & 1403 \\
\hline & 100 & 1 & 0.59 & 0.57 & 9.78 & 1189 \\
\hline \multirow[t]{6}{*}{ Crushed Silt } & 0 & 0.03 & 0.71 & 0.70 & 0.16 & 12 \\
\hline & 0 & 0.5 & 0.67 & 0.66 & 0.82 & 76 \\
\hline & 0 & 1 & 0.66 & 0.60 & 1.65 & 118 \\
\hline & 100 & 0.03 & 0.73 & 0.73 & 7.94 & 628 \\
\hline & 100 & 0.5 & 0.71 & 0.68 & 8.69 & 576 \\
\hline & 100 & 1 & 0.67 & 0.67 & 8.80 & 689 \\
\hline \multirow[t]{9}{*}{ Precipitated Silt } & 0 & 0.03 & 10.04 & 8.42 & 0.04 & 3 \\
\hline & 0 & 0.5 & 9.77 & 6.68 & 0.41 & 26 \\
\hline & 0 & 1 & 10.26 & 5.54 & 0.93 & 56 \\
\hline & 50 & 0.03 & 9.41 & 7.51 & 1.31 & 113 \\
\hline & 50 & 0.5 & 8.49 & 6.38 & 1.78 & 141 \\
\hline & 50 & 1 & 9.23 & 5.19 & 2.38 & 256 \\
\hline & 100 & 0.03 & 9.75 & 7.71 & 5.48 & 863 \\
\hline & 100 & 0.5 & 9.63 & 6.36 & 6.46 & 724 \\
\hline & 100 & 1 & 10.28 & 5.72 & 8.01 & 1025 \\
\hline \multirow[t]{9}{*}{ Kaolinite } & 0 & 0.03 & 1.07 & 0.91 & 0.02 & 2 \\
\hline & 0 & 0.5 & 1.05 & 0.71 & 0.27 & 28 \\
\hline & 0 & 1 & 1.16 & 0.65 & 0.43 & 33 \\
\hline & 50 & 0.03 & 1.08 & 0.99 & 0.77 & 267 \\
\hline & 50 & 0.5 & 1.16 & 0.89 & 1.03 & 243 \\
\hline & 50 & 1 & 1.14 & 0.81 & 1.24 & 256 \\
\hline & 100 & 0.03 & 1.17 & 0.95 & 2.39 & 747 \\
\hline & 100 & 0.5 & 1.17 & 0.84 & 2.89 & 814 \\
\hline & 100 & 1 & 1.17 & 0.74 & 2.94 & 1810 \\
\hline
\end{tabular}

THF hydrate since there is no possibility that the excess liquid will freeze.

[11] The vapor pressure of THF is six to seven times higher than that of water. This situation can lead to experimental difficulties related to preferential evaporation of THF. We conducted extensive experiments to determine the potential impact of THF evaporation. The results showed that stirred THF + water had a slower evaporation rate than stirred, pure THF and that pure THF under static conditions still had a lower evaporation rate than stirred, pure THF. We thus ran our experiments with no agitation of the liquid and kept the solution preparation time to less than $120 \mathrm{~s}$ to further minimize evaporation. Considering the potential impact of evaporation during specimen preparation, the hydrate concentrations in this study are expected to be $S_{\text {hyd }} \cong 52$ and $98 \%$ when we target specimens with nominal 50 and $100 \%$ hydrate-filled porosity.

\subsection{Specimen Preparation and Test Procedure}

[12] Specimen preparation procedures differed for different sediments. For the sand specimen (sample diameter $\sim 3.5 \mathrm{~cm}$; sample height $\sim 7 \mathrm{~cm}$ ), the sand was air pluviated inside a latex membrane, which was already fixed to the lower cap in the triaxial cell, and was then filled with the appropriate THF-water solution. Then, the top cap was emplaced, an instant vacuum applied to make the membrane and specimen stand erect, and the specimen mold was removed. The kaolinite, crushed silt, and precipitated silt specimens were prepared by thoroughly mixing the dry soils with the selected THF-water solution to form a saturated paste. Fluid-saturated filter paper strips were placed around the kaolinite and precipitated silt specimens to facilitate drainage. Regardless of the sample composition, we measured the initial geometry of the specimen and glued the lateral strain gauge to two diametrically opposite points at midheight before closing the chamber.

[13] The triaxial cell was then filled with mineral oil. Each specimen was isotropically consolidated to the target effective stress until drainage ceased. Void ratios at specimen preparation and after consolidation are summarized in Table 1.

[14] After consolidation, specimens were frozen to $-10^{\circ} \mathrm{C}$ under constant effective confining pressure. The thermocouples permitted us to monitor temperature changes in the sample, and an exothermic reaction usually occurred $6-8$ hours after cooling, indicating the formation of THF hydrate. The system was then stabilized for an additional 12 hours. The specimen with $S_{\text {hyd }}=0 \%$ hydrate-filled porosity ( $100 \%$ water) was not subjected to freezing. The estimated volume expansion of the fluid after phase transformation is $\sim 3.5 \%$ for the fluid mixture used to attain $S_{\text {hyd }}=50 \%$, and $\sim 7.3 \%$ for the fluid in $S_{\text {hyd }}=100 \%$.

[15] Finally, specimens were subjected to deviatoric loading at constant mass. The axial strain was monitored with a linear variable displacement transducer, and the deviatoric load was measured with a load cell, both mounted outside the chamber (Figure 2). The deviatoric stress was applied to impose strain rates of $0.1 \%$ per minute $\left(\sim 1.7 \times 10^{-5} \mathrm{~s}^{-1}\right)$ in 

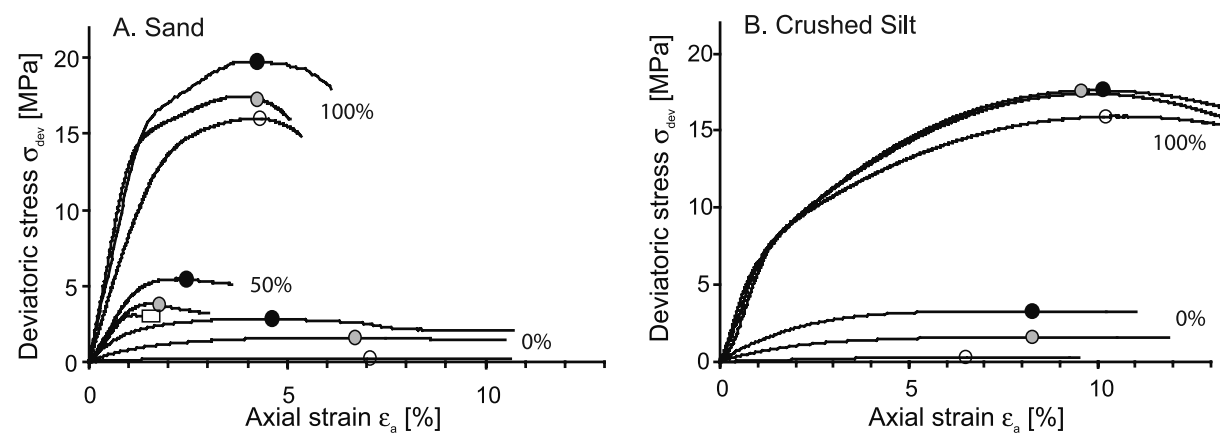

C. Precipitated Silt
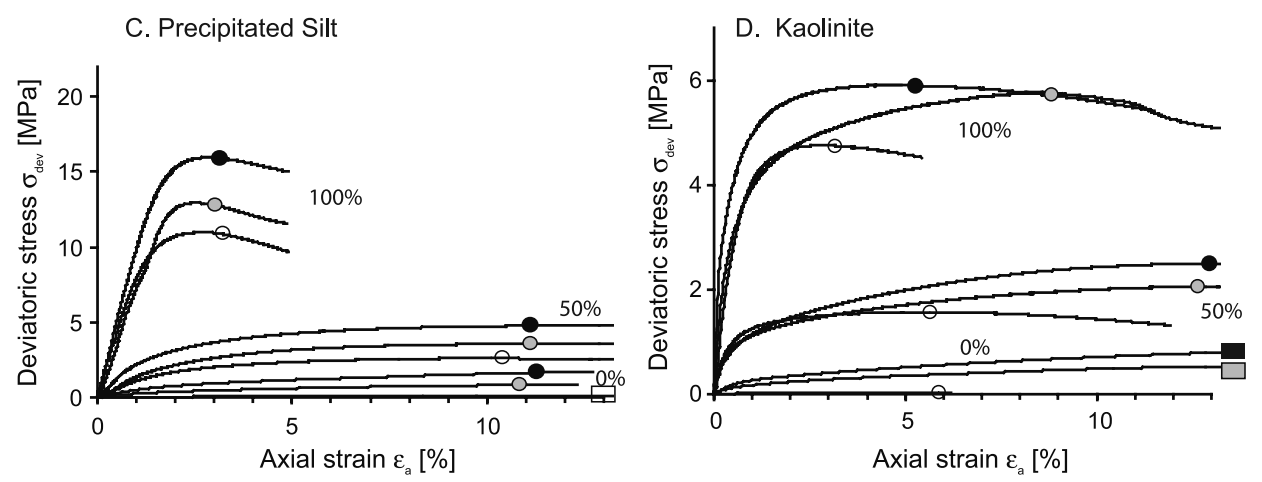

Figure 4. Stress and axial strain as measured on the different soils with different hydrate concentrations $(0,50$, and $100 \%)$ and at different confining pressures. The circles on the curves denote the peak response for $0.03 \mathrm{MPa}$ (open circles), $0.5 \mathrm{MPa}$ (gray circles), and $1 \mathrm{MPa}$ (solid circles). At axial strains that exceed these peak values, strain localization is expected. For experiments in which the peak value was not reached, the maximum axial strain at which measurements were conducted is denoted by a rectangle with the same shading scheme as the circles. Note that the results for kaolinite are plotted on a different scale.

specimens with $S_{\text {hyd }}=0 \%$ hydrate-filled porosity and $1 \%$ per minute $\left(\sim 1.7 \times 10^{-4} \mathrm{~s}^{-1}\right)$ in specimens with $S_{\text {hyd }}=50$ and $100 \%$. For the duration of this part of the test $(<20$ minutes for specimens containing hydrate), the triaxial cell was kept between -7 and $-10^{\circ} \mathrm{C}$ with a cooling pack. After testing, specimens were visually inspected to measure volume and cross-sectional area and to identify the failure mode and any heterogeneities (for example, ice or hydrate lenses).

\section{Results}

\subsection{Stress-Strain Relationships and Modes of Failure}

[16] Deviatoric stress $\sigma_{\text {dev }}\left(=\sigma_{1}-\sigma_{3}\right)$ versus axial strain $\varepsilon_{\mathrm{a}}$ curves (Figure 4 ) obtained during deviatoric loading for all tested specimens and confining pressures $\left(\sigma_{0}^{\prime}=0.03,0.5\right.$ and $1 \mathrm{MPa}$ ) reveal hardening with increasing strain for specimens lacking hydrate. A comparison of samples without hydrate to those containing different amounts of hydrate indicates that the peak strength of the specimens increases nonlinearly with increases in the amount of hydrate-filled porosity.

[17] Figure 4 also demonstrates that hydrate-bearing sediments exhibit high stiffness at low strains. The range of deviatoric stress values at failure under different confining pressures becomes narrower as hydrate concentration increases, and the stress-strain response becomes less sensitive to confining pressure.
[18] As the hydrate-filled porosity increases to $S_{\mathrm{hyd}}=$ $100 \%$, increasing strain leads to different behavior in the sand and crushed silt specimens than in precipitated silt and kaolinite. The sand and crushed silt specimens have a yield point before peak strength. This yield point separates two regions of different tangential stiffness (see section 4.1). The initial quasi-elastic high-stiffness region extends to an axial strain of $\varepsilon_{\mathrm{a}} \approx 1 \%$, regardless of confining pressure. Ting et al. [1983] and Andersen et al. [1995] have reported similar stress-strain behaviors for frozen water-saturated sand specimens, and Parameswaran et al. [1989] and Cameron et al. [1990] show this relationship for sand containing THF hydrate. For our hydrate-bearing specimens, the yield point may correspond to hydrate-particle debonding or the local breakage of hydrate in the pore space, while the peak strength indicates the global structural collapse of the soil-hydrate system. On the basis of published work, it is anticipated that strain localization begins at the first yield point [Ting et al., 1983; Cameron et al., 1990]. Precipitated silt specimens having 100\% hydrate-filled porosity exhibit a greater tendency for quasibrittle behavior.

[19] Specimens with $S_{\mathrm{hyd}}=50$ and $100 \%$ hydrate-filled porosity consolidated to $\sigma_{0}^{\prime}=0.03 \mathrm{MPa}$ show vertical fractures similar to those commonly reported in rock tests at low confinement. At $\sigma_{0}^{\prime}=0.5 \mathrm{MPa}$, the specimens had clear shear planes at failure. Finally, the sand specimens with $100 \%$ hydrate-filled porosity developed a fracture network at $\sigma_{0}^{\prime}=1 \mathrm{MPa}$. 

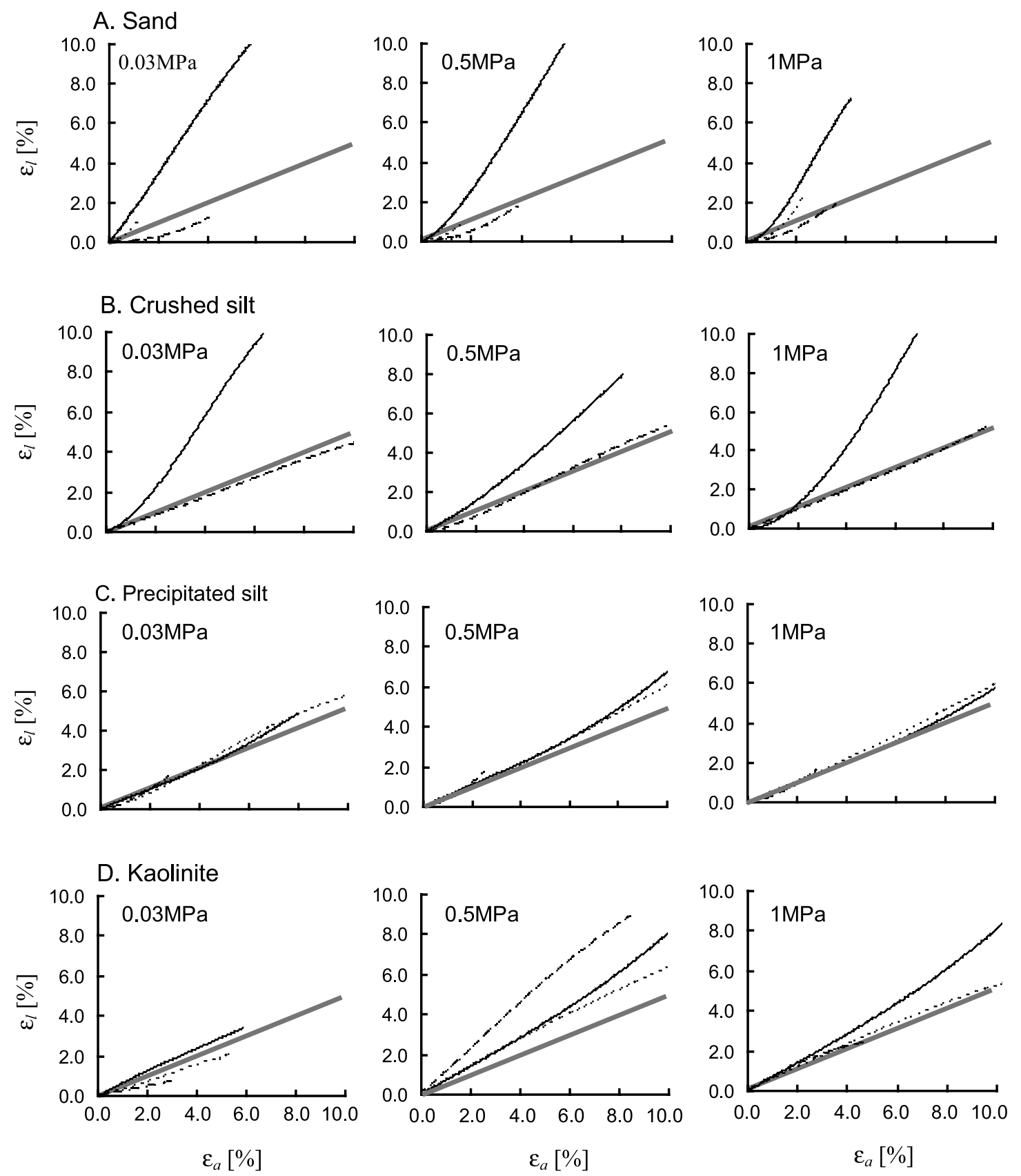

Figure 5. Strain response for tested specimens with different hydrate concentration and subjected to various confining stresses. The solid line is $0 \%$ hydrate-bearing sediment, dotted line denotes $50 \%$ hydrate-bearing sediments, and dashed line represents $100 \%$ hydrate-bearing sediments. The gray lines have a slope of 0.5 , corresponding to Poisson's ratio of 0.5 , and indicate the trend expected for a specimen sheared at constant volume and experiencing homogeneous deformation.

[20] We observed no lenses or other noticeable heterogeneities during visual inspection of any of the tested specimens. Rapid freezing and elevated effective confining pressure appear to promote self-homogenization during hydrate formation.

\subsection{Evolution of Lateral and Axial Strain}

[21] Figure 5 summarizes the evolution of the lateral strain $\varepsilon_{1}$ at the midplane versus the average axial strain $\varepsilon_{\mathrm{a}}$. Trends reveal the effects of soil type, confinement, hydrate concen- tration, and possible testing difficulties. The reference line for $\varepsilon_{1} / \varepsilon_{\mathrm{a}}=0.5$ is superimposed on the plots to represent cylindrical deformation at constant volume; specimens that plot above this line experience large lateral strain because they (1) deform at constant volume but in barrel shape owing to friction against end platens; (2) experience shear band formation; or (3) dilate owing to unavoidable local cavitation upon shear dilation or to potential experimental problems with inadequate liquid-phase saturation. 


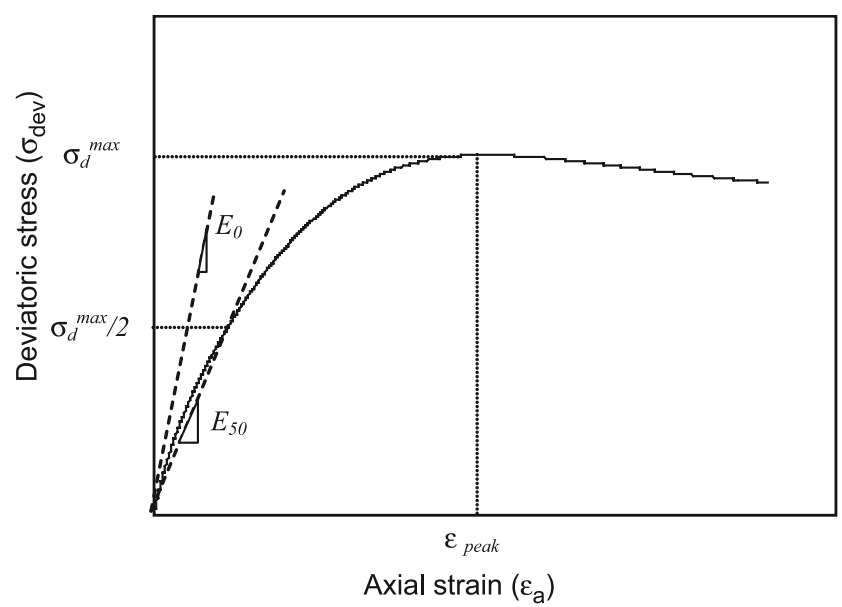

Figure 6. Graphical explanation for the different measures of stiffness (Young's modulus) used in the geotechnical literature.

[22] The non-hydrate-bearing crushed silt and sand specimens exhibit the largest lateral strain. The onset of significant lateral deformation occurs at higher axial strains with increasing hydrate concentration. Hydrate concentration does not affect strain evolution in precipitated silt, which appears to shear at constant volume. When hydrate cements the granular skeleton, the increased contractive behavior with increased confinement competes against hindered lateral deformation.
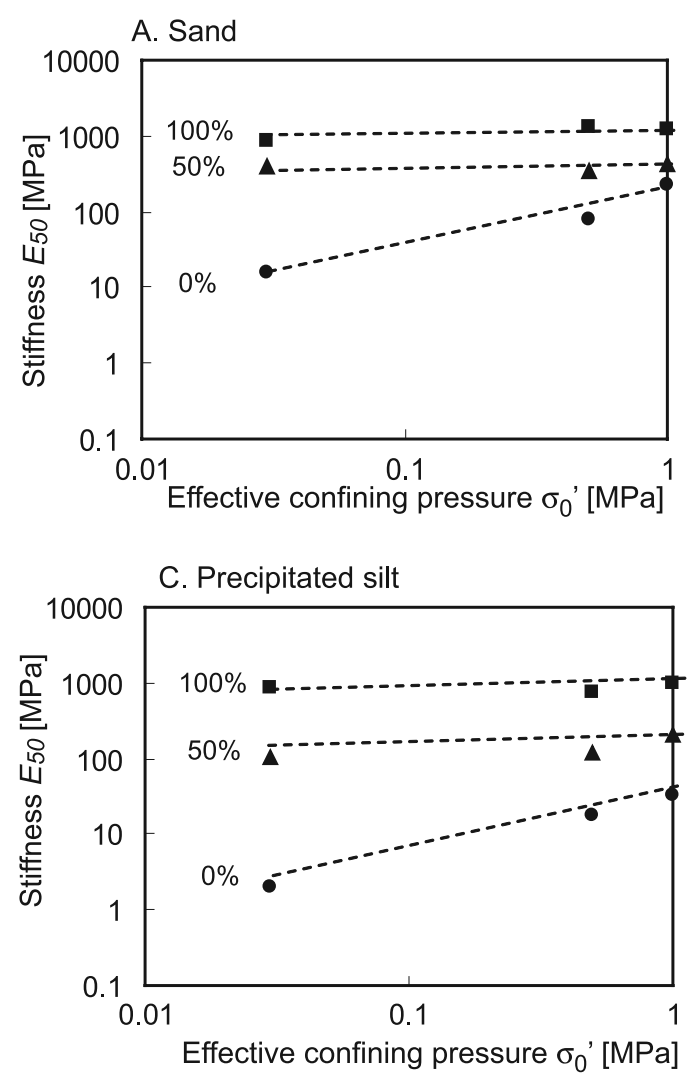

[23] Other measurement difficulties may also affect the trends shown in Figure 5, including membrane penetration in the coarser soils and poor contact between the specimen and endcaps that can affect the measured axial strains $\varepsilon_{\mathrm{a}}$ at low-strain levels. Taken together, we caution against interpretation of results presented in Figure 5 in terms of standard measures of Poisson's ratio.

\section{Discussion}

[24] Starting with the first-order observations of stressstrain curves, we can constrain the modulus of elasticity and strength parameters for hydrate-bearing sediments.

\subsection{Stiffness and Stiffness Degradation}

[25] The stiffness of a material is its resistance to deformation. The modulus of elasticity $E_{0}$ is often used to describe material stiffness, but $E_{0}$ applies only to the elastic part of the stress-strain curve. The tangential modulus $E_{\tan }=$ $\Delta \sigma_{\mathrm{dev}} / \Delta \varepsilon_{\mathrm{a}}$ can be determined at any point along the stressstrain curve and is always less than or equal to $E_{0}$, as demonstrated in Figure 6. Mathematically, the initial $E_{0}$ is the value of $E_{\tan }$ at the origin, but we cannot determine $E_{0}$ from the external measurements of deformation in our experiments owing to sitting/bedding effects. Figure 6 also illustrates the meaning of the secant modulus $E_{50}$, which is determined at half the peak deviatoric stress $\sigma_{\mathrm{dev}}^{\max } / 2$ drawn through the origin of the stress-strain curve.

[26] Figure 7 and Table 1 show the variations in secant stiffness $E_{50}$ with confinement and hydrate concentration for our specimens. The results demonstrate that the stiffness
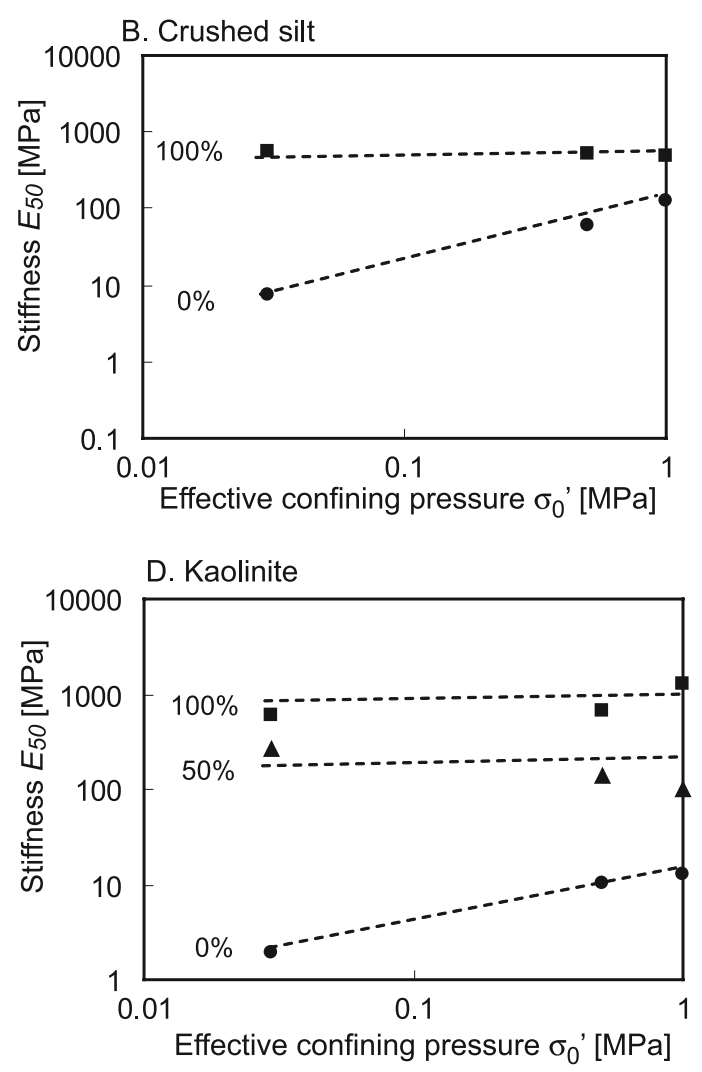

Figure 7. Secant stiffness $E_{50}$ at $\sigma_{\mathrm{dev}}^{\max } / 2$ as a function of effective confining pressure $\sigma_{0}^{\prime}$. 


\section{A. Sand specimens}
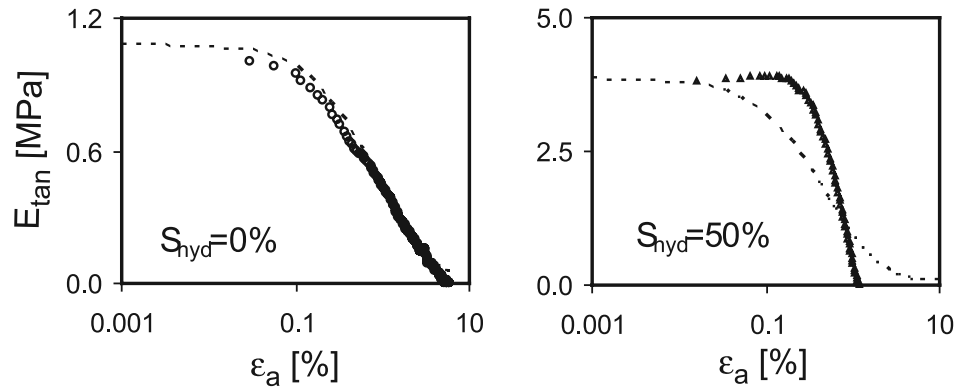

B. Kaolinite specimens

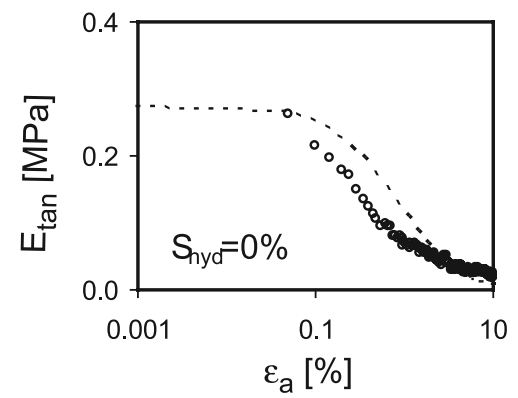

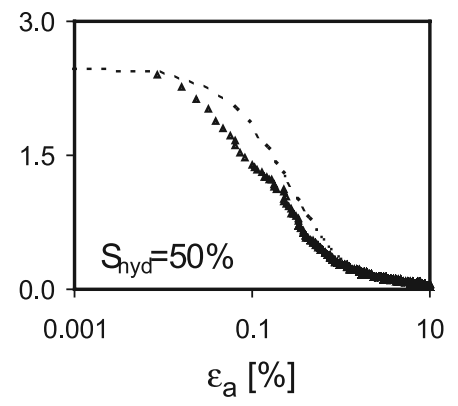
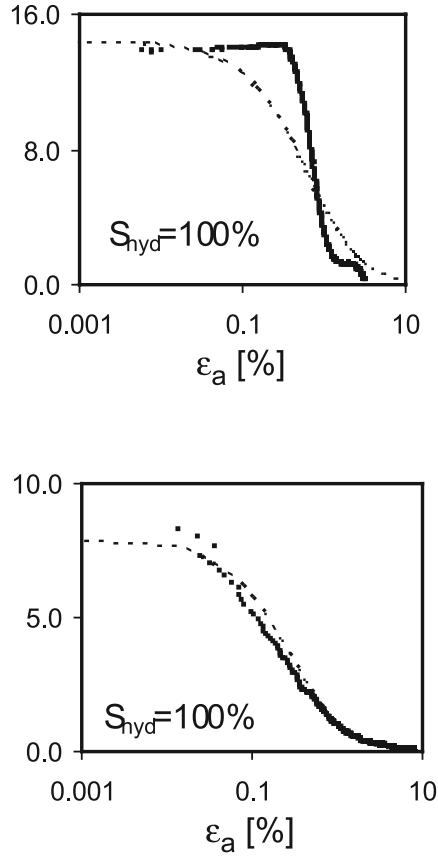

Figure 8. The variation of tangential stiffness $E_{\mathrm{tan}}$ as a function of axial strain $\varepsilon_{\mathrm{a}}$ under effective confining pressure $\sigma_{0}^{\prime}=0.5 \mathrm{MPa}$ for (a) sand and (b) kaolinite containing different concentrations of synthetic hydrate in pore space. The dotted lines represent the hyperbolic model. The results for crushed silt (not shown) closely resemble those for sand.

of sediments without hydrate is governed by confining pressure; increasing confining pressure leads to increases in interparticle coordination, contact area and frictional resistance, and consequent increases in skeletal stiffness. However, hydrate controls the bulk stiffness of the material in the presence of high concentrations of hydrate, and confining pressure has a negligible impact in these cases.

[27] Hyperbolic-type models are often used to capture the degradation of the tangential stiffness $E_{\tan }$ as a function of increasing axial strain in uncemented soils [Duncan and Chang, 1970; Shibuya et al., 1991]:

$$
E_{\mathrm{tan}}=E_{0}\left[1+\frac{\varepsilon_{\mathrm{a}}}{\tau_{\max } / E_{0}}\right]^{-2} .
$$

Figure 8 demonstrates that hydrate-bearing sands deviate from the smooth and gradual stiffness degradation predicted by the hyperbolic model. A sharp drop of $E_{\tan }$ is observed in hydrate-bearing sands, similar to the behavior observed for cemented sands in the work of Airey and Fahey [1991] and Tatsuoka and Shibuya [1991]. However, only gradual stiffness degradation with strain is observed for hydrate-bearing kaolinite, possibly owing to the weak bonding between kaolinite and hydrate.

\subsection{Shear Strength: The Effect of Drainage}

[28] The peak shear strength $q_{\max }=\left(\sigma_{\operatorname{dev}}^{\max } / 2\right)$ is given in Figure 9 and Table 1 for all tested soils. In the absence of hydrates, the shear strength is of frictional nature and depends on confining pressure. When hydrate is present, $q_{\max }$ increases with hydrate concentration and becomes somewhat independent of confining pressure in soils with 50 and $100 \%$ hydrate-filled porosity. Note that there is some influence of effective stress even on specimens for which $S_{\text {hyd }}=100 \%$ : The higher effective confinement $\sigma_{0}^{\prime}$ reached during the consolidation phase leads to lower void ratio and higher interparticle coordination prior to hydrate formation, hence higher strength.

[29] Drainage, backpressure, and the measurement of pore fluid pressure generation may be affected by hydrate formation in the tubing that connects the specimen to pore pressure transducers or external ports. We avoided such experimental problems by running undrained tests without backpressure, using carefully saturated specimens. Nonetheless, the strain data shown in Figure 5 still suggest the development of dilation in several specimens, possibly because of inadequate saturation or even cavitation. We therefore explore the implications of pore pressure generation on strength by considering both drained and undrained bounds to the shear strength.

[30] The Coulomb strength criterion $\tau$ in granular sediments is defined in terms of the normal effective stress $\sigma_{\mathrm{n}}^{\prime}$ and material parameters that capture cementation $c$ and frictional contributions $\phi$ to strength:

$$
\tau=c+\sigma_{\mathrm{n}}^{\prime} \tan \phi=c+\left(\sigma_{\mathrm{n}}-u\right) \tan \phi .
$$

The excess pore water pressure $u$ during deviatoric loading is given by:

$$
u=B\left[\Delta \sigma_{3}+A\left(\Delta \sigma_{1}-\Delta \sigma_{3}\right)\right],
$$



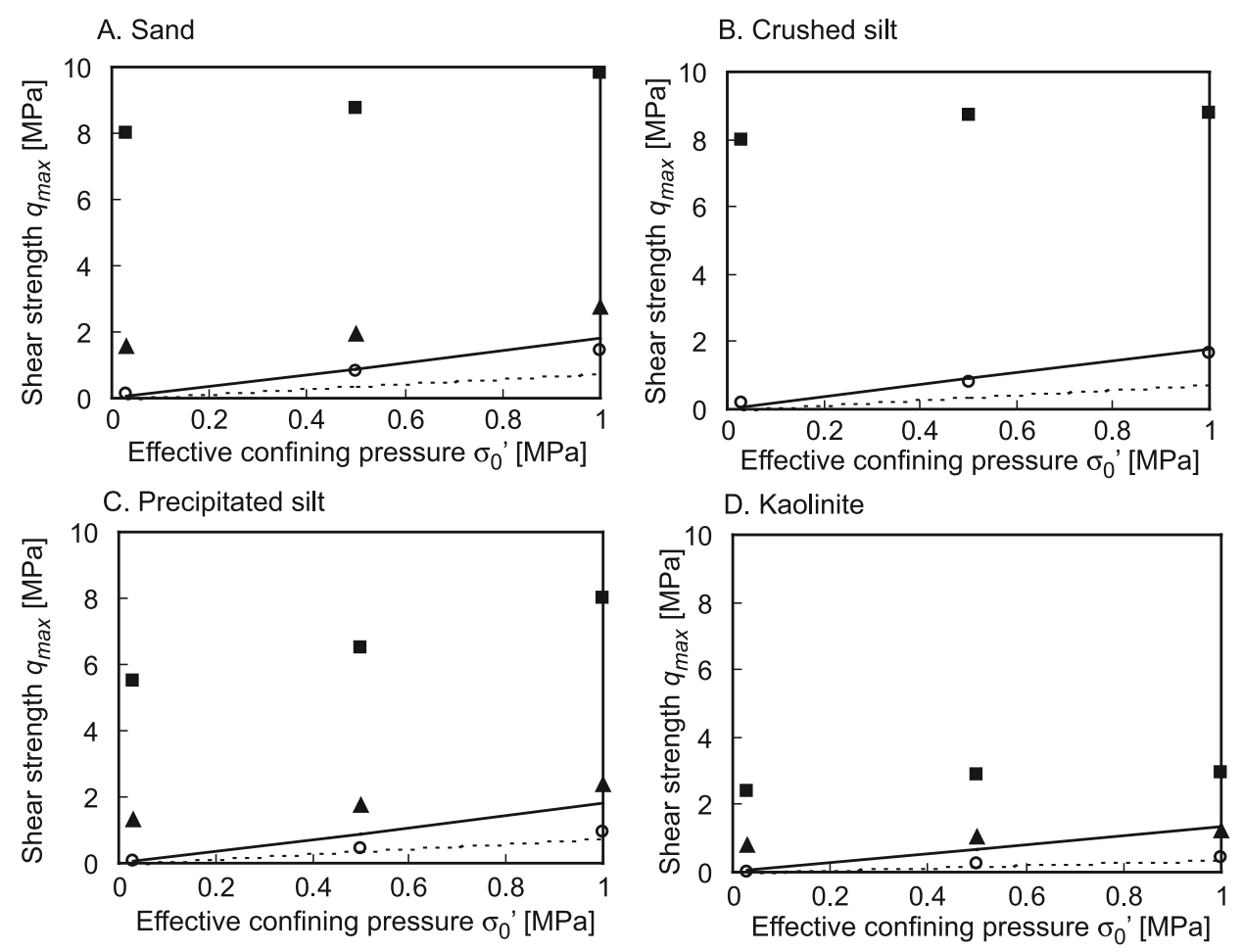

Figure 9. Shear strength versus effective confining pressure and hydrate-filled porosity for (a) sand, (b) crushed silt, (c) precipitated silt, and (d) kaolinite. The continuous and dotted lines represent the range between drained and undrained strength values for frictional behavior, corresponding to $c=0$ in equations (5) and (6). Open circles denote $0 \%$ hydrate, triangles $50 \%$, and squares $100 \%$.

where $A$ and $B$ are Skempton's pore pressure parameters [Skempton, 1954; Lambe and Whitman, 1969]. Combining equation (3) with Coulomb's failure criterion, the maximum shear stress a saturated specimen $(B=1)$ may sustain in a triaxial compression test is determined by the effective confining stress $\sigma_{0}^{\prime}$, the cementing strength $c$ contributed by hydrates, the angle of internal shear strength $\phi$, and Skempton's $A$ parameter at failure $A_{\mathrm{f}}$ :

$$
\frac{q_{\max }}{\sigma_{\mathrm{o}}^{\prime}}=\frac{c \cos (\phi) / \sigma_{\mathrm{o}}^{\prime}+\sin (\phi)}{1+\left(2 A_{\mathrm{f}}-1\right) \sin (\phi)} .
$$

At low hydrate concentration $S_{\text {hyd }}$, the cementation component can be disregarded $\left(c / \sigma_{0}^{\prime} \approx 0\right)$, and the strength becomes:

$$
\frac{q_{\max }}{\sigma_{\mathrm{o}}^{\prime}}=\frac{\sin (\phi)}{1-\sin (\phi)},
$$

for drained conditions and, for undrained conditions,

$$
\frac{q_{\max }}{\sigma_{\mathrm{o}}^{\prime}}=\frac{\sin (\phi)}{1+\left(2 A_{\mathrm{f}}-1\right) \sin (\phi)} .
$$

These bounds are shown in Figure 9 assuming that $A_{\mathrm{f}}=$ 0.4 for sand, crushed silt, and precipitated silt and $A_{\mathrm{f}}=1$ for kaolinite. From this analysis we conclude that the measured shear strength of sand and crushed silt specimens without hydrate is close to the drained shear strength. On the other hand, the measured shear strength of precipitated silt and kaolinite without hydrates resembles the undrained strength.

[31] When hydrate concentration approaches $S_{\text {hyd }}=$ $100 \%$, the shear strength is determined by the cementing strength of hydrates. Disregarding the frictional component, both the drained and undrained strengths are given by:

$$
q_{\max }=c,
$$

from equation (4). Hence drainage conditions have a minor effect on the measured strength of specimens with high concentrations of hydrate.

[32] Equations (4) and (7) predict that the presence of hydrates has a higher impact on the normalized strength when the sediment is subjected to lower effective stress. Indeed, while the normalized strength for sediments without hydrates typically ranges between 0.2 and 2 (undrained to drained), the measured normalized strength for the $S_{\text {hyd }}=$ $100 \%$ hydrate-bearing sand varies from $q_{\max } / \sigma_{0}^{\prime}=9.8$ at $\sigma_{0}^{\prime}=1 \mathrm{MPa}$ to $q_{\max } / \sigma_{0}^{\prime}=270$ when the sand is subjected to $\sigma_{0}^{\prime}=0.03 \mathrm{MPa}$, in shallow burial.

\subsection{Stiffness and Strength Dependency on Hydrate Concentration}

[33] Figures 7 and 9 demonstrate that hydrate formation has greater proportional impact on both the stiffness and strength of sediments at lower initial effective confining pressure, but the effect does not appear to be linear with 


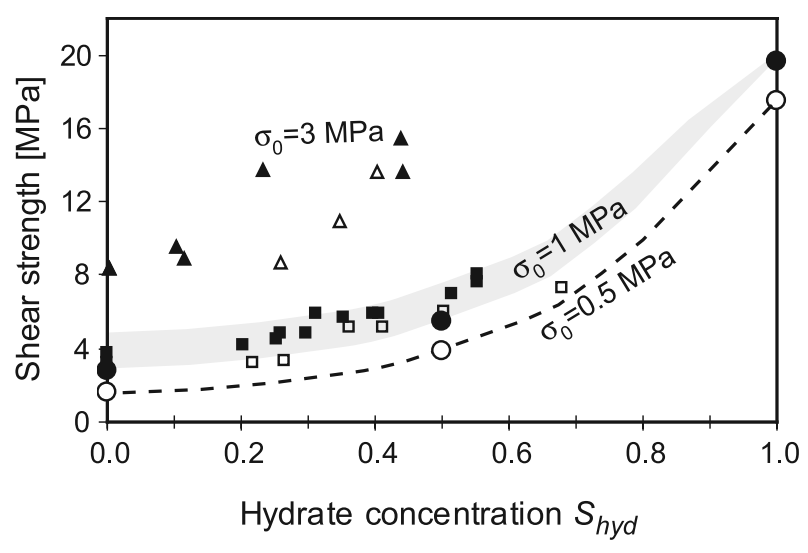

Figure 10. Shear strength as a function of hydrate concentration for three effective confining pressures $(0.5$, 1 , and $3 \mathrm{MPa}$ ). The methane hydrate results for $\sigma_{0}^{\prime}=1 \mathrm{MPa}$ are from Masui et al. [2005], and the results for $\sigma_{0}^{\prime}=3 \mathrm{MPa}$ are from Ebinuma et al. [2005]. Solid triangles and squares denote sand mixtures with methane hydrate formed by gas percolation, and open triangles and squares represent methane hydrate formed from ice seeds. Filled circles show the sand-THF hydrate data from this study at $1 \mathrm{MPa}$ (solid) and at $0.5 \mathrm{MPa}$ (open circles). The mean sediment diameter $D_{50}$ is $220 \mu \mathrm{m}$ for Ebinuma et al. [2005] and $250 \mu \mathrm{m}$ for Masui et al. [2005], significantly larger than $D_{50}=120 \mu \mathrm{m}$ for the sand used in our THF experiments.

hydrate concentration. Our previous work [Yun et al., 2005] used simultaneous compressional wave $V_{\mathrm{p}}$ and shear wave $V_{\mathrm{s}}$ velocity measurements in sand specimens to infer that hydrate formation from dissolved THF initially occurs not at grain contacts, but in pore space and probably on grain surfaces, and that hydrate then grows into the pore space. Yun et al. [2005] observed that the most significant changes in $V_{\mathrm{s}}$ occur once the hydrate concentration exceeds $S_{\text {hyd }} \sim 40 \%$, implying that hydrate exerts the greatest impact on the skeletal stiffness of the specimens after this point. Similar results were obtained by Berge et al. [1999] using hydrate of the refrigerant R11.

[34] Figure 10 shows shear strength data for sands, confined at $1 \mathrm{MPa}$, with either THF hydrate (this study) or methane hydrate [from Masui et al., 2005]. The methane-hydrate-bearing sands were formed either from unsaturated sands or with the ice-seed method. It can be seen that the most pronounced increase in strength is expected when $S_{\text {hyd }}$ exceeds $>50 \%$, in agreement with the velocity data discussed above. Furthermore, the data show that there are minor differences between the strength of THF-hydrate-bearing and methane-hydrate-bearing sands and that stronger methane-hydrate-bearing specimens are obtained when unsaturated sands are used rather than the ice-seed method. The effect of hydrate-formation history on the properties of hydrate-bearing sediments can be explored at the pore scale. For example, formation of methane hydrate by percolation of a gaseous phase preferentially produces gas hydrate at grain contacts, which leads to higher stiffness and greater strength at lower hydrate concentrations than does formation of hydrate from aqueous phase methane.

\subsection{Stiffness-Strength Correlation}

[35] The dependence of strength and stiffness on initial effective confinement $\sigma_{0}^{\prime}$ and hydrate concentration $S_{\text {hyd }}$ suggests a correlation between shear strength $q_{\max }$ and the secant stiffness $E_{50}$. This correlation is explored in Figure 11, where the results obtained with all tested specimens are shown together. The best fitting power relationship is $E_{50}=96\left(q_{\max }\right)^{1.13}$, but a simpler linear expression is $E_{50} \cong 100 q_{\max }$. Note that the data indicate significant deviations from these trends, indicating the need to independently measure strength and stiffness.

\subsection{Specific Surface Effects}

[36] Our results reveal that strength and, in particular, the cementation parameter $c$ decrease with increasing specific surface $S_{\mathrm{a}}$. A similar trend has been previously observed in frozen soils [Wijeweera and Joshi, 1990]. Various mechanisms may contribute to the correlations among strength, cementation, and sediment specific surface for hydrates, including limited mineral-to-hydrate bonding strength and difficulty forming hydrate (and water ice) in the small pores within high specific surface sediments [Clennell et al., 1999]. In the specific case of THF hydrate, if water molecules were preferentially attracted to the mineral surface, soil mixtures with THF $17 \mathrm{H}_{2} \mathrm{O}$ solution would lead to incomplete hydrate formation with excess of liquid THF, particularly in high specific surface clayey sediments. The effective number of water molecules per molecule of THF becomes:

$$
n=R\left[1-\frac{S_{\mathrm{a}} d \rho_{\mathrm{w}}}{w c}\right]
$$

where $R=17$ is the optimal ratio between THF and water, $S_{\mathrm{a}}$ denotes soil specific surface, $d$ represents the thickness of the adsorbed layer, $\rho_{\mathrm{w}}$ is water density, and $w c$ denotes the

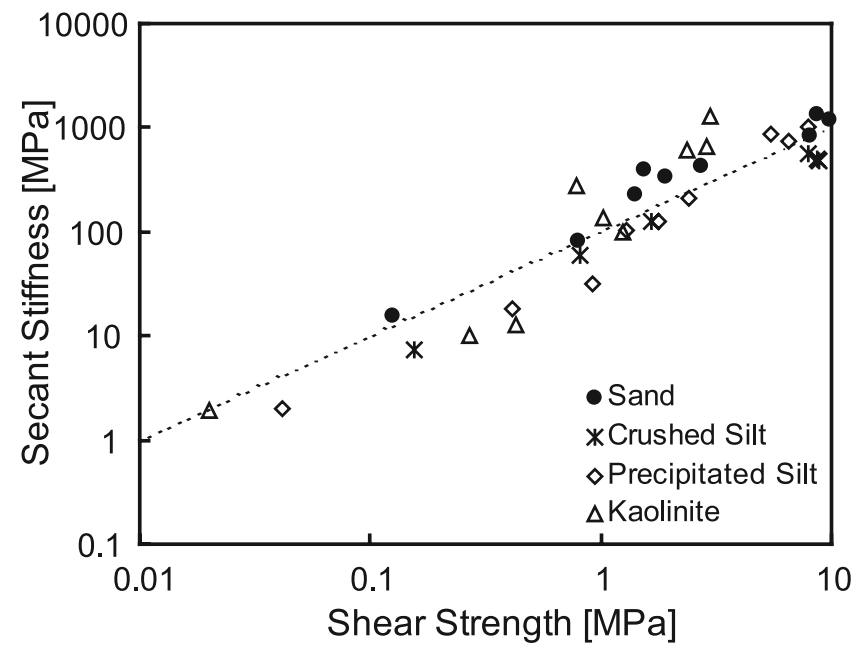

Figure 11. Secant stiffness $E_{50}$ at $\sigma_{\mathrm{dev}}^{\max } / 2$ as a function of shear strength for all tested soils, with and without hydrates, and at all confining pressures. The dotted line corresponds to $E_{50} \cong 100 q_{\max }$. 


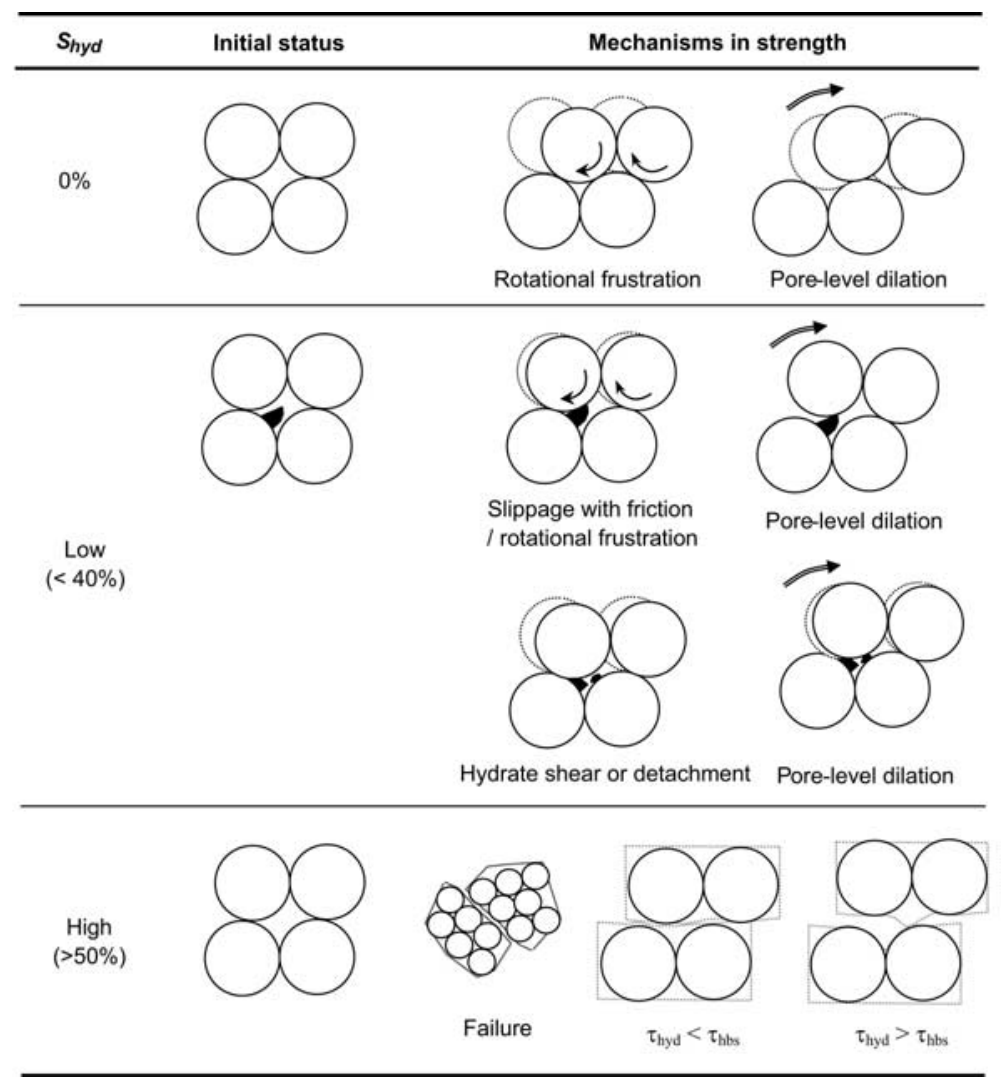

Figure 12. Possible particle-level mechanisms controlling the shear strength of hydrate-bearing sediments at various concentrations.

volumetric water content in the soil. For $d=5 \times 10^{-10} \mathrm{~m}$, the estimated $n$ values to produce $S_{\text {hyd }}=100 \%$ hydrate filling voids are $n=17.00$ for sand $(w c \sim 0.2)$ but $n=17.76$ for kaolinite $(w c \sim 0.4)$.

\subsection{Hypothetical Particle-Level Mechanisms}

[37] Figure 12 illustrates several hypothetical particlelevel mechanisms that might explain the dependence of shear strength on hydrate concentrations:

[38] $\bullet$ In the absence of hydrates, $S_{\text {hyd }} \sim 0 \%$, shear causes particle rotation, slippage, and rearrangement. So-called rotational frustration in densely packed sediments is overcome by either dilation (low confinement) or slippage (high confinement). The mechanism by which the sample deforms at a micromechanical level is governed by the energy minimization principle.

[39] - At low hydrate concentration $\left(S_{\text {hyd }}<40 \%\right)$, hydrate crystals may shear, may detach from the mineral surface, or may interfere with rotation. The impact of these mechanisms on dilation and strength depends on the hydrateparticle bonding strength, on the strength of hydrate itself, and on hydrate concentration.

[40] - At high hydrate concentration $\left(S_{\text {hyd }}>50 \%\right)$, the cementing strength provided by the hydrate mass, the bonding between particles and hydrates, and the hydrate-occupied porosity govern deformation and strength response. A shear plane develops through the hydrate mass when hydrate strength is smaller than the hydrate-grain bonding strength. In this case, hydrate strength dominates the overall strength evolution. On the other hand, failure occurs along the hydrate-particle interface when hydrate strength is greater than the hydrate-grain bonding strength. This is the most likely case when smooth particles or high specific surface soils are involved, such as in kaolinite specimens.

In all cases, the presence of hydrate promotes or enhances dilation.

\section{Conclusions}

[41] Systematic laboratory testing of sand, precipitated and crushed silt, and clay containing well-controlled concentrations of THF hydrate and subjected to various confining pressures leads to the following results:

[42] - Soil type, confining pressure, and hydrate concentration in the pore space determine the load-deformation response of hydrate-bearing sediments.

[43] - A clear yield point is identified before the peak strength, particularly for $100 \%$ hydrate-bearing sand and crushed silts. This yield point is associated with hydrateparticle debonding before the soil structural collapse at peak strength. In these cases, specimens experience a sudden drop in stiffness during deformation, and the stiffness degradation deviates from the simple hyperbolic-type model. Kaolinite (fine-grained soil) more closely follows a hyperbolic-type stress-strain model, suggesting weaker hydrate-to-mineral bonding.

[44] - The lower the effective confining stress, the greater the impact hydrates exert on the normalized strength. The 
cementation contribution to the shear strength of hydratebearing sediments decreases with increasing specific surface of soil minerals.

[45] - The midstrain level stiffness shows a clear correlation with the shear strength in hydrate-bearing sediments. The value of the ratio is $E_{50} / q_{\max } \approx 100$ for our data. However, there are pronounced deviations from this trend, and independent measurements of stress and stiffness are required in the design of experiments.

[46] - The evolution of lateral and axial strains hints that unsaturated conditions either preexist or develop during shear deformation in some of our specimens. At high hydrate concentrations, the impact of drainage conditions on measured strength is limited.

[47] - Stress-dependent soil skeletal stiffness and frictional strength dominate the mechanical properties of hydratebearing sediments at low hydrate concentration $\left(S_{\text {hyd }}<40 \%\right)$. However, the behavior becomes more independent of stress at high hydrate concentration $\left(S_{\text {hyd }}>50 \%\right)$ when the presence of hydrates controls both stiffness and strength.

[48] - At high hydrate concentration $S_{\text {hyd }}$, the presence of hydrates in the pore space enhances the strength, the stiffness, and possibly the dilative tendency of sediments by increasing interparticle coordination, by cementing particles together, and by filling the pore space.

[49] Acknowledgments. This research was sponsored by a contract to C.R. and J.C.S. from the Joint Industry Project for Methane Hydrate, administered by ChevronTexaco with funding from award DE-FC2601NT41330 from DOE's National Energy Technology Laboratory. The Goizueta Foundation at Georgia Tech also provided support for this work. We thank A. Palamino for the SEM photos in Figure 1, and the reviewers and R. Birchwood for comments that improved this manuscript. The research was completed while C.R. was on assignment at and wholly supported by the National Science Foundation (NSF). All findings are those of the authors and do not reflect the views of the DOE or NSF.

\section{References}

Airey, D. W., and M. Fahey (1991), Cyclic response of calcareous soils from the north-west shelf Australia, Geotechnique, 41(1), 101-121.

Andersen, G. R., C. W. Swan, C. C. Ladd, and J. T. Germaine (1995), Small-strain behavior of frozen sand in triaxial compression, Can. Geotech. J., 32, 428-451.

Berge, L. I., K. A. Jacobsen, and A. Solstad (1999), Measured acoustic wave velocities of R11 (CCl3F) hydrate samples with and without sand as a function of hydrate concentration, J. Geophys. Res., 104, 15,41515,424 .

Buffett, B. A., and O. Y. Zatsepina (2000), Formation of gas hydrate from dissolved gas in natural porous media, Mar. Geol., 164, 69-77.

Cameron, I., Y. P. Handa, and T. H. W. Baker (1990), Compressive strength and creep behavior of hydrate-consolidated sand, Can. Geotech. J., 27, $255-258$

Carey, F. A. (1987), Organic Chemistry, McGraw-Hill, New York.

Chand, S., T. A. Minshull, D. Gei, and J. M. Carcione (2004), Elastic velocity models for gas-hydrate bearing sediments-A comparison, Geophys. J. Int., 159, 573-590, doi:10.1111/j.1365-246X.2004.02387.x.

Chand, S., T. A. Minshull, J. A. Priest, A. I. Best, C. R. I. Clayton, and W. F. Waite (2006), An effective medium inversion algorithm for gas hydrate quantification and its application to laboratory and borehole measurements of gas hydrate-bearing sediments, Geophys. J. Int., 166, 543-552, doi:10.1111/j.1365-246X.2006.03038.x.

Clennell, M. B., M. Hovland, and J. S. Booth (1999), Formation of natural gas hydrate in marine sediments 1 . Conceptual model of gas hydrate growth conditioned by host sediment properties, J. Geophys. Res., 104(10), 22985-23003.

Devarakonda, S., A. Groysman, and A. S. Myerson (1999), THF-water hydrate crystallization: An experimental investigation, J. Cryst. Growth, 204, 525-538.

Duncan, J. M., and C. Y. Chang (1970), Nonlinear analysis of stress and strain in soils, J. Soil Mech. Found. Div. Am. Soc. Civ. Eng., 96(SM5), $1629-1653$
Durham, W. B., S. H. Kirby, L. A. Stern, and W. Zhang (2003a), The strength and rheology of methane clathrate hydrate, J. Geophys. Res., 108(B4), 2182, doi:10.1029/2002JB001872.

Durham, W. B., L. A. Stern, and S. H. Kirby (2003b), Ductile flow of methane hydrate, Can. J. Phys., 81, 373-380.

Durham, W. B., L. A. Stern, S. H. Kirby, and S. Circone (2005), Rheological comparisons and structural imaging of sI and sII end-member gas hydrates and hydrate/sediment aggregates, Proc. Fifth Int. Conf. Gas Hydrates, 2, 607-614, paper 2030, Trondheim, Norway.

Ebinuma, T., Y. Kamata, and H. Minagawa (2005), Mechanical properties of sandy sediment containing methane hydrate, Proc. Fifth Int. Conf. Gas Hydrates, Trondheim, Norway.

Ecker, C., J. Dvorkin, and A. M. Nur (2000), Estimating the amount of gas hydrate and free gas from marine seismic data, Geophysics, 65(2), $565-573$.

Goto, S., F. Tatsuoka, S. Shibuya, Y.-S. Kim, and T. Sato (1991), A simple gauge for local small strain measurements in the laboratory, Soil Found., $31,169-180$

Gough, S. R., and D. W. Davidson (1971), Composition of tetrahydrofuran hydrate and the effect of pressure on the decomposition, Can. J. Chem., 49, 2691-2699.

Guimaraes, M. (2001), Crushed stone fines and ion removal from clay slurries, Ph.D. thesis, Georgia Institute of Technology, Atlanta, Georgia. Helgerud, M. B., J. Dvorkin, and A. Nur (1999), Elastic-wave velocity in marine sediments with gas hydrates: Effective medium modeling, Geophys. Res. Lett., 26, 2021-2024.

Hyndman, R. D., and G. D. Spence (1992), A seismic study of methane hydrate marine bottom simulating reflectors by vertical fluid expulsion, J. Geophys. Res., 97, 6683-6698.

Klein, K. (1999), Electromagnetic Properties of High Specific Surface Minerals, Ph.D. thesis, Georgia Institute of Technology, Atlanta, Georgia. Lambe, T. W., and R. V. Whitman (1969), Soil Mechanics, John Wiley, Hoboken, N. J., 553 pp.

Lee, M. W. (2002), Biot-Gassmann theory for velocities of gas hydratebearing sediments, Geophysics, 67(6), 1711-1719.

Lee, M. W., and T. S. Collett (2001), Elastic properties of gas hydratebearing sediments, Geophysics, 66(3), 763-771.

Masui, A., H. Haneda, Y. Ogata, and K. Aoki (2005), The effect of saturation degree of methane hydrate on the shear strength of synthetic methane hydrate sediment, Proc. Fifth Int. Conf. Gas Hydrates, Trondheim, Norway.

Mi, Y., A. Sakai, R. Walia, R. D. Hyndman, and S. R. Dallimore (1999), Vertical seismic profiling and seismic properties of gas hydrate in an Arctic well, CREWES Res. Rep., 11, 52.

Parameswaran, V. R., M. Paradis, and Y. P. Handa (1989), Strength of frozen sand containing tetrahydrofuran hydrate, Can. Geotech. J., 26, $479-483$.

Parks, G. A. (1990), Surface energy and adsorption at mineral-water interfaces: An introduction, in Mineral-Surface Interface Geochemistry, 23 , edited by M. F. Hochella Jr. and A. F. White, pp. 133-175, Mineralogical Society of America, Chantilly, Virginia.

Pearson, C., J. Murphy, and R. Hermes (1986), Acoustic and resistivity measurements on rock samples containing tetrahydrofuran hydrates: Laboratory analogues to natural gas hydrate deposits, J. Geophys. Res., 91, 14,132-14,138

Pecher, I. A., and W. S. Holbrook (2000), Seismic methods for detecting and quantifying marine methane hydrate/free gas reservoirs, in Natural Gas Hydrate in Ocean and Permafrost Environments, edited by M.D. Max, pp. 275-292, Springer, New York.

Priest, J. A., A. I. Best, and C. R. I. Clayton (2005), A laboratory investigation into the seismic velocities of methane gas hydrate-bearing sand, J. Geophys. Res., 110, B04102, doi:10.1029/2004JB003259.

Rueff, R. M., and E. D. Sloan (1985), Effect of granular sediment on some thermal properties of tetrahydrofuran hydrate, Ind. Eng. Chem. Process Des. Dev., 24, 882-885.

Santamarina, J. C., and G. C. Cho (2001), Determination of critical state parameters in sandy soils-simple procedure, Geotech. Test. J., 24(2), $185-192$.

Shibuya, S., F. Tatsuoka, F. Abe, Y. S. Kim, C. S. Park, and J. N. Mukabi (1991), A new look at stress-strain relations of soils and soft rocks, Ninth Asian Reg. Conf. Soil Mech. Found. Eng., Bangkok, Thailand.

Skempton, A. W. (1954), The pore-pressure coefficients A and B, Geotechnique, 4, 143-147.

Smallwood, I. M. (1996), Handbook of Organic Solvent Properties, Halsted, New York.

Spangenberg, E., and J. Kulenkampff (2005), Physical properties of gas hydrate bearing sediments, Proc. Fifth Int. Conf. Gas Hydrates, Tronheim, Norway.

Spangenberg, E., J. Kulenkampff, R. Naumann, and J. Erzinger (2005), Pore space hydrate formation in a glass bead sample from methane 
dissolved in water, Geophys. Res. Lett., 32, L24301, doi:10.1029/ 2005GL024107.

Stern, L. A., and S. H. Kirby (1998), Polycrystalline methane hydrate: Synthesis from superheated ice and low temperature mechanical properties, Energy and Fuels, 12, 201-211.

Sun, C.-Y., G.-J. Chen, and L.-Y. Liang (2004), Interfacial tension of methane + water with surfactant near the hydrate formation conditions, J. Chem. Eng. Data, 49, 1023-1025, doi:10.1021/je049948p.

Tatsuoka, F., and S. Shibuya (1991), Deformation characteristics of soils and rocks from field and laboratory tests, Ninth Asian Regional Conference on Soil Mechanics and Foundation Engineering, 2, Bangkok, Thailand.

Ting, J. M., R. T. Martin, and C. C. Ladd (1983), Mechanisms of strength for frozen sand, J. Geotech. Eng., 109(10), 1286-1302.

Waite, W. F., B. J. deMartin, S. H. Kirby, J. Pinkston, and C. D. Ruppel (2002), Thermal conductivity measurements in porous mixtures of methane hydrates and quartz sand, Geophys. Res. Lett., 29(24), 2229 , doi:10.1029/2002GL015988.

Waite, W. F., W. J. Winters, and D. H. Mason (2004), Methane hydrate formation in partially water saturated Ottawa sand, Am. Mineral., 89, $1202-1207$.

Winters, W. J., I. A. Pecher, W. F. Waite, and D. H. Mason (2004), Physical properties and rock physics models of sediment containing natural and laboratory-formed methane gas hydrate, Am. Mineral., 89, $1221-1227$

Wijeweera, H., and R. C. Joshi (1990), Compressive strength behavior of fine-grained frozen soils, Can. Geotech. J., 27, 472-483.

Woods, C. E. (2004), Examination of the effects of biosurfactant concentration on natural gas hydrate formation in seafloor porous media, M.S thesis, Mississippi State University, Mississippi State, Mississippi.

Yun, T. S., F. M. Francisca, J. C. Santamarina, and C. Ruppel (2005), Compressional and shear wave velocities in uncemented sediment containing gas hydrate, Geophys. Res. Lett., 32, L10609, doi:10.1029/ 2005GL022607.

Yun, T. S., G. A. Narsilio, J. C. Santamarina, and C. Ruppel (2006), Instrumented pressure chamber for characterizing sediment cores recovered at in situ hydrostatic pressure, Mar. Geol., 229, 285-293, doi:10.1016/ j.margeo.2006.03.012.

Zhong, Y., and R. E. Rogers (2000), Surfactant effects on gas hydrate formation, Chem. Eng. Sci., 55, 4175-4187.

C. Ruppel (corresponding author), U.S. Geological Survey, 384 Woods Hole Rd., Woods Hole, MA 02543, USA. (cruppel@usgs.gov)

J. C. Santamarina and T. S. Yun, School of Civil and Environmental Engineering, Georgia Tech, 710 Atlantic Drive, NW, Atlanta, GA $30332-$ 0355, USA. (carlos@ce.gatech.edu; taesup.yun@ce.gatech.edu) 